\title{
Aspectual and focal functions of Cognate-Head-Dependent Constructions: Evidence from Africa
}

\author{
Oliver Bond \& Gregory D. S. Anderson
}

\begin{abstract}
Cognate-Head-Dependent Constructions (CHDCs) are employed across numerous genera in Africa to signpost alternations in the aspectual characteristics of a predicate or the information focus of a clause. The co-occurrence of a finite lexical verb (the cognate head) and an etymologically related (deverbal) noun or non-finite verb form (the cognate dependent) in such structures is interpreted with reference to the scalar semantics of events and properties. Within this areal typology, CHDCs are employed to indicate either (i) a high point relative to a norm on a semantic scale, or (ii) a conventionally low-ranked possibility, in order to implicitly contrast possible alternatives.
\end{abstract}

\section{Keywords}

aspect, cognate, Cognate-Head-Dependent Constructions, dependent, exclusive focus, finiteness, head, pluractionality, polarity focus, scalar semantics, verb focus

\section{How to cite this article:}

Bond, Oliver and Gregory D. S. Anderson. In press. Aspectual and focal functions of Cognate-Head-Dependent Constructions: Evidence from Africa. Linguistic Typology, 18. 


\section{Introduction}

Cognate-Head-Dependent-Constructions (CHDCs) are syntactic configurations in which the finite lexical verb form heading the predicate of a clause (i.e. the COGNATE HEAD) licences a dependent phrase, that comprises an etymologically and lexically related (deverbal) noun or non-finite verb form (i.e. a COGNATE DEPENDENT of that head). Evidence from a wide range of African languages indicates that constructions meeting this definition are commonly used to express alternations in ASPECT or FOCUS. For instance, in Gidar (Biu-Mandara; Cameroon), cognate dependent forms are obligatorily employed in predicate focus constructions, such as (1a). In this example, which answers the question 'What did he do with this thing?', the infinitival verb áddò 'to reheat' precedes the finite form of the cognate head àdónì 'reheat' (itself composed of a verbal stem, a subject prefix and an object suffix). Crucially, when the infinitive is not present, as in (1b), the predicate is not in focus (Frajzyngier 2008: 372-3). ${ }^{1}$

$$
\text { Gidar }
$$

a. Context: In answer to 'What did he do with this thing?'

$$
\begin{array}{ll}
\text { áddò } & \text { à-dó-nì } \\
\text { INF.reheat(CD) } & \text { 3.MASC-reheat-3SG.MASC.OBJ(CH) }
\end{array}
$$

'He reheated it.' (Frajzyngier 2008: 372)

\section{b. à-dóhò-nú-kò}

3.MASC-reheat-3SG.MASC.OBJ-PFV

'He reheated it.' (Frajzyngier 2008: 149)

In this paper, we present a typology of related semantic and information-structural alternations marked by cognate dependents (henceforth CDs) that are licensed by cognate heads (henceforth $\mathrm{CHs}$ ). Our central claim is that CDs occur primarily in contexts where scalar semantics are employed to rank and exclude salient alternative meanings.

We begin in $\S 2$ by setting out the domain of investigation. Next, in $\S 3$, we examine data from languages in which CHDCs are employed to modify aspectual characteristics of the clause, namely to express event plurality and the attainment of event goals. ${ }^{2}$ Specifically we provide evidence that CHDCs are used to encode event iteration (§3.1), event frequency and property proclivity $(\S 3.2)$, scalar attainment of a goal (§3.3) and endpoint attainment of a goal (§3.4). Then, in §4, we show how CHDCs are employed for the purpose of focus manipulation. Evidence is presented that they are used for three

\footnotetext{
${ }^{1}$ Objects and infinitival complements usually follow the verb in Gidar - unless in focus, in which case they occur pre-verbally and usually also precede the subject; this demonstrates that the discourse function of the cognate dependent is partly determined by its syntactic distribution. The somewhat irregular alternation between the forms of the verbal stem in (1a) and (1b) is discussed by Frajzyngier (2008: 148-149).

${ }^{2}$ In such cases, the use of CHDCs is functionally similar to certain instances of iconic reduplication whereby the presence of "more of the same" form (in this case a cognate dependent form) signals intensity or quantification of an event.
} 
focus related goals: verb/predicate focus $(\S 4.1)$, polarity focus $(\S 4.2)$ and exclusive focus $(\S 4.3)$. Discussion of the links between the aspectual and focal domains of their use is provided in $\S 5$.

\section{Domain of study}

We use the following morphosyntactic characteristics to delimit the domain of investigation discussed in this paper:

\section{Morphosyntactic domain of study}

Any clause comprising a (finite) element functioning as the lexical head of a predicate (cognate head or $\mathrm{CH}$ ) that licenses a syntactically dependent non-subject phrase containing a less finite lexical head (cognate dependent or CD) that (i) exhibits lexemic identity with, or a derivationally related form to, the lexical head of the predicate with which it occurs, and (ii) does not obligatorily occur with every instance of the cognate head.

This morphosyntactic domain is defined to limit the scope of the research to clauses in which there is ASYMMETRY IN FINITENESS between (i) the element functioning as the lexical head of the clause, and (ii) the lexical head of a syntactically dependent phrase. ${ }^{3}$ As such, the $\mathrm{CH}$ will exhibit more morphosyntactic and morphosemantic properties of finiteness than the CD. Canonical and non-canonical properties of finiteness are outlined in Nikolaeva (2013). Asymmetries in finiteness between a CH and CD are defined on the basis of language specific properties. For instance, in the Oromo (Eastern Cushitic; Ethiopia) example in (2a), the CH fiigde 'run' is identifiable partly on the basis of its inflectional properties - it bears inflection indicating the gender and number of the subject and aspect of the verb - whereas the CD fiigičča 'run' does not have any inflectional exponence.
Oromo
a. ijoollee bakka-kana-tti fiig-ičča
fiig-de children.FEM.NOM place-DEM-LOC run-DEP(CD) run-3.FEM.PFV(CH) 'Children ran (running) at this place.' (Fufa 2009: 111)
b. ijoollee
bakka kana-tti fiig-de
children.FEM.NOM place DEM-LOC run-3.FEM.PFV
'Children ran at this place.' (Fufa 2009: 109)

Similarly, in the Gidar example in (1a), the CH àdónì 'reheat' bears inflectional morphology indicating the person and gender of the subject and the person, gender and number of the object, while the CD áddo 'reheat' is not inflected for these properties.

\footnotetext{
${ }^{3}$ We use the term "head" not "verb" to capture the fact that in some constructions, the lexical head of the predicate is not a verb, but an adjective or noun. We use the term "lexical" to acknowledge the distinction between "lexical" and "functional" heads.
} 
Establishing a finiteness asymmetry of this kind is important for the domain of study because some dependent verb forms are formed through zero derivation and clearly resemble 'verb copying' (see $\S 3.2$ and $\S 4.1$ for examples and discussion). In such cases, only one verb is anticipated to have the full inflectional exponence of a finite verb. ${ }^{4}$ This restriction also ensures that the (stylistic) repetition of finite verb forms is excluded from the research domain.

The lexical relationship between the $\mathrm{CH}$ and $\mathrm{CD}$ can be characterised by the fact that they are either manifestations of the SAME LEXEME (i.e. they exhibit LEXEMIC IDENTITY and thus have the same lexical entry) or manifestations of DERIVATIONALLY RELATED LEXEMES (i.e. they have distinct lexical entries, but one is derived from the other), whereby the CD is usually the derived form. ${ }^{5}$ Word-forms that are not linked by a relationship of this kind are therefore beyond the scope of the present study. ${ }^{6}$ This approach allows us to treat the direction of derivation and finiteness as logically independent variables. Therefore, regardless of the exact morphological makeup of the word-form employed as the lexical head of the predicate and/or the morphological structure of the dependent form, the only necessary relation between the forms is that they transparently share a root or stem (although suppletive stems are at least theoretically possible). ${ }^{7}$ Given this definition of CDs, they may comprise morphological characteristics associated with any type of dependent form, such as INFINITIVES, GERUNDS, PARTICIPLES, and (DEVERBAL) NOUNS. This includes derivation through concatenative and non-concatenative processes, as well as zero-derivation. For example, in (2a) the CD bears a derivational suffix -ičča on the root fiig, indicating that it is a lexical derivative of the CH (Fufa 2009: 111). Similarly, in (1a) the CD bears the infinitive prefix $2-$, whereas the $\mathrm{CH}$ is underived.

Finally, to ensure that the presence vs. absence of a CD is associated with an alternation in meaning, the morphosyntactic domain used here only includes constructions where the co-occurrence of a given verb with a lexically related dependent form is NOT ALWAYS OBLIGATORY. While verbs with mandatory CDs are ultimately of interest in a full exposition of this phenomenon - particularly from a diachronic perspective - they may represent fixed combinations with idiosyncratic behaviour, and do not necessarily reflect the general processes of interest to the current investigation. For instance, the functional alternation between (1a) and (1b) arises because the presence of a preverbal $\mathrm{CD}$ is not always obligatory with this verb.

\footnotetext{
${ }^{4}$ Since finiteness may also be indicated through the presence of tense/aspect particles or auxiliaries, finiteness is not only a morphological property of lexical heads.

${ }^{5}$ The (uni)direction of derivation is almost exceptionless in the data examined, with a only handful of aberrant examples. In such cases the head of the relevant dependent phrase is a noun, and is reportedly an object of the cognate head (for instance, see Amha 2001: 207).

${ }^{6}$ For instance, since hyponymous objects do not meet this criterion, they are not discussed here (see Hale \& Keyser (2002: 70-72, 88-89) for discussion).

${ }^{7}$ Although less restrictive, we necessarily leave open the idea that the head of the predicate and the head of the dependent phrase share the same lexical entry since it may not always be possible to distinguish between lexemic identity and zero-derivation on principled grounds. However, it is possible to distinguish CHs from their CDs in terms of their finiteness potential.
} 
The different construction types under investigation here share the property that the lexical verb of a predicate LICENSES a (non-subject) dependent form that is lexically (but not necessarily inflectionally) identical or derivationally related to the verb by which it is licensed. We view licensing as a stipulation of the conditions under which the presence of one linguistic expression permits the presence of a second dependent form. While licensing primarily concerns constraints on argument structure (and thus which arguments can be subcategorised for by a verb) it is clear that, by virtue of co-occurrence restrictions in CHDCs, the properties of the $\mathrm{CH}$ necessarily determines properties of the $\mathrm{CD}$ in CHDCs even when the CD is not a core argument. In the Gidar example in (1a), the preverbal infinitive must necessarily be a lexical derivative of the head of the predicate to express verb/predicate focus (i.e. it cannot be an infinitive of some other verb). This indicates that some sort of licensing constraint restricts the syntactic and semantic properties of the dependent phrase. Without a licensing constraint the domain of investigation would include structures where the use of a $\mathrm{CD}$ with a $\mathrm{CH}$ is coincidental, rather than directly constrained by grammar (e.g. if a less-finite subordinate clause happens to contain the same verb as the more finite main clause, without any systematic grammaticalised semantic or information-structural effect).

An obvious consequence of this broad view of CHDCs is that without further stipulation the domain subsumes constructions containing dependent forms that have the core argument function of object. "Cognate objects" are well attested in the languages of Africa (see for instance, Schuh (1998), Manfredi (1991), Lefebvre \& Brousseau (2002), Hale et al. (1995), Newman (2000), Jaggar (2001), Hiraiwa (2005), Kandybowicz (2008), Heath (2008), amongst others). Despite some similarity between cognate objects and other types of $\mathrm{CD}$, we acknowledge that cognate objects may have an origin and behaviour that is distinct from the types of dependents discussed in this paper. Unlike the majority of CDs we discuss, cognate objects are typically restricted to occurring with certain sub-classes of verbs, often characterised as being "unergative". ${ }^{9}$ While in some languages cognate objects are always required by the verb that licenses them (see Faraclas (1984: 53), Faraclas \& Williamson (1984: 6, 13), Storch (2009: 128-130)) the research domain delimited here requires that CDs are not obligatory with every occurrence of the $\mathrm{CH}$. For some authors, the Cognate Object Construction (COC) embodies a relation defined in syntactic and semantic terms independently of any phonological similarity or lexical relatedness between the verb and object. With this in mind, it is important to make clear that etymological cognacy is an essential characteristic of the CHDCs discussed in this paper. To avoid unintended contention, we draw our examples from languages where the cognate dependents discussed do not exhibit the behaviour

\footnotetext{
${ }^{8}$ Examples in which a verb and its subject are lexically-related are occasionally attested with certain weather predicates, (e.g. in Ma'di (Blackings \& Fabb 2003: 87)). Examples in which cognate dependents function as the grammatical subject of a clause are also attested in passive constructions (e.g. see Fufa (2009) for examples from a range on languages of Ethiopia), but, with the exception of weather predicates, we are not aware of examples of "cognate subjects" where the argument cognate with the CH could not also be the object of an underived verb. If such examples exist, they are rare.

${ }^{9}$ Not all all authors agree on this characterisation, for instance, see Levin \& Rappaport Hovav (1994) Kuno \& Takami (2004).
} 
associated with typical core arguments in that language. Such examples provide the most convincing evidence in support of a relationship between CHDCs and the scalar semantics associated with the expression of aspect $(\S 3)$ and focus $(\S 4)$.

\section{Event plurality and scalar attainment}

Our survey of the aspectual functions of CDs in African languages reveals that they are frequently employed in constructions that indicate EVENT PLURALITY - the expression of the multiplicity or quantification of events or event phases - and SCALAR ATTAINMENT - the degree of attainment of a goal relative to a contextually or conventionally defined norm. The semantic domain of event plurality is closely associated with that of VERBAL PluRALiTy (Jespersen 1924, Dressler 1968, Cusic 1981, Corbett 2000) a term usually associated with the presence of morphological exponents of plurality as part of the verb (e.g. affixes, reduplication, etc.). ${ }^{10}$ In this section, we present evidence that CDs are used within a variety of languages to indicate the multiplicity or quantification of events, independently of morphological exponents of plurality. We demonstrate that iconic uses of CDs indicating event iteration (§3.1), event frequency or property proclivity $(\S 3.2)$ can be conceptually linked to associated uses of CDs that do not involve event plurality. We argue that uses of CDs to indicate scalar attainment, either the scalar attainment of a goal (§3.3) or completion of an event to a logical endpoint (\$3.4), are similar to those used for event plurality by virtue of referencing a high point relative to a norm on an ordered semantic scale.

\subsection{Event iteration}

Event iteration involves the repetition of an event or event phase on a single occasion (Bybee et al. 1994: 100). Iterated events indicated by CDs are found across several regions of sub-Saharan Africa, including East, Central and West Africa. For instance, the use of a CD to express event iteration is among the attested functions of preverbal cognate infinitives in Sheko (North Omotic; Ethiopia). In (3), the presence of the cognate verbal nominal óskà (labelled as an infinitive following Hellenthal 2010: 10) indicates that calling was iterated several times, suggesting that the event described by the predicate has been conceptually structured into quantified performance units or event phases. ${ }^{11}$

\footnotetext{
${ }^{10}$ The precise domain of verbal plurality differs from author to author. Intensity is included in the domain of verbal plurality by Dressler (1968) and Cusic (1981). Xrakovskij (1997: 7-8) sees intensity as one of three logically independent semantic attributes of quantitative aspectuality, multiplicity and duration.

${ }^{11}$ Verbal nominals (of the infinitival type) can be derived from all verbs by the suffix $-a$ and the use of a HL tone pattern. The verbal nominal in (3) contrasts with the regular deverbal noun óskú 'call' (Hellenthal 2010: 174). However, given that Sheko is strictly verb-final, both objects and infinitives appear in preverbal position.
} 
(3)

Sheko

Context: the phone was out of order.

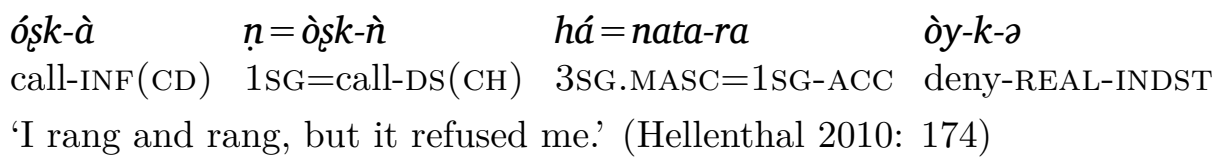

In Kaamba (Bantoid; Congo), preverbal cognate infinitives are used in progressive constructions to "renforcer l'idée de répétition dans le déroulement de l'action" ["reinforce the idea of repetition within the action"] (Bouka 1989: 237, cited in Hadermann 1996: 160), leading to the alternation in (4), where the CD sàlá precedes the inflected $\mathrm{CH}$ if iteration is part of the predicate semantics.

Kaamba

a. wà-múr-sàlá

CL1-PROG-work

'Il est en train de travailler.' [He is working.]

b. sàlá

kà-mút-sàlá

work.INF(CD) CL1-PROG-work(CH)

'Il est en train de travailler.' [He is working (involving repetition).] (Bouka 1989, cited in Hadermann 1996: 160)

In Mbay (Bongo-Bagirmi; Chad, Central African Republic), cognate infinitives occur in constructions that quantify events (see also §3.2). These include performance units that are restarted or repeated. For instance, in (5), each $\mathrm{CH}$ and its object is followed by a CD and the adverbial phrase ká kijà 'again' to indicate event iteration. ${ }^{12}$

$$
\text { Mbay }
$$

a. j̀y bòr k-j̀y ká kìjò

gather $(\mathrm{CH})$ mud INF-gather(CD) again

'He began gathering mud again.'

b. ùr $\quad$ wàa $\quad k$-ùr $\quad k a ́$ kìjà

grind $(\mathrm{CH})$ millet INF-grind(CD) again

'She began pounding millet again.' (Keegan 1997: 148)

The co-occurrence of CDs with adverbials indicating repetition (as in (5) for instance) and/or exponents of imperfective or habitual aspect is common across the languages investigated. In such cases, it is not possible to attribute the iterative semantics of

\footnotetext{
${ }^{12}$ The basic word order in Mbay is SVO (Keegan 1997: 154). In transitive clauses, direct objects immediately follow the verb, while indirect objects may either directly follow the verb and precede the direct object or alternatively follow both the verb and the direct object. Adverbials follow all other elements in the phrase or occur in sentence initial position (Keegan 1997: 146-7).
} 
the clause solely to the presence of the CD. ${ }^{13}$ This should not be considered evidence against the observations made here regarding the aspectual functions of CHDCs, since, in a cross-linguistic survey of this kind, we would expect to find constructions at various stages of grammaticalisation.

In Hausa (West Chadic; Nigeria), quantified, iterated events may be counted using numeral modifiers. For instance, in (6) the numeral ukù 'three' modifies the deverbal noun zāgì 'insulting'. Crucially, the quantified element here is the event, not a particular abstract entity (i.e. 'an insult').

$$
\begin{aligned}
& \text { Hausa }
\end{aligned}
$$

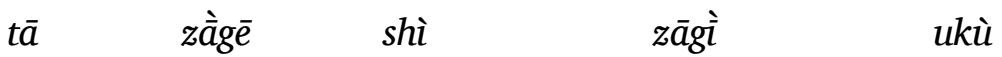

$$
\begin{aligned}
& \text { 3SG.FEM insult(CH) 3SG.MASC.OBJ insult.ger(CD) three } \\
& \text { 'She insulted him three times.' (Newman 2000: 387) }
\end{aligned}
$$

Quantification of an event into performance units is a fairly common property of constructions containing CDs. Iterated events are clearly quantified in this way, since they consist of at least two event units. Frequently recurring events are also characterised in terms of repeated event units (§3.2). Despite this, they are rarely counted with numerals.

\subsection{Event frequency and property proclivity}

Another form of quantification associated with event plurality is found in formations where a CD is used to indicate a high point on a continuous scale of event iteration and/or event frequency relative to some norm. ${ }^{14}$ This is represented schematically in Figure 1.

Figure 1: Semantic scale for event frequency

REFERENCED HIGH POINT ON A SCALE

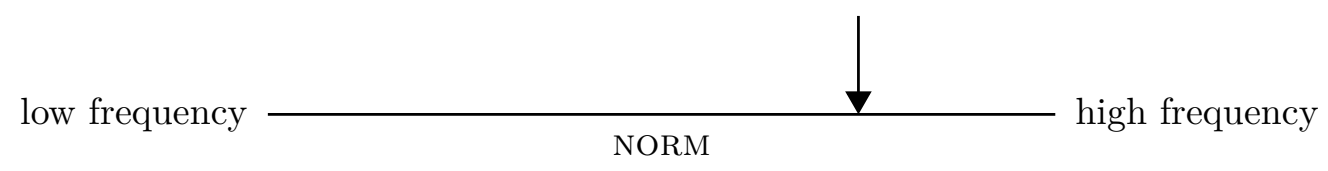

Evidence for this use of CHDCs comes from Bongo-Bagirmi, Nilotic and Berber languages. For instance, in certain Mbay constructions with definite subjects, CDs are associated with quantification of an event to an 'excessive degree' (Keegan 1997: 151) as in (7). ${ }^{15}$ Here the $\mathrm{CH}$ is preceded by a cognate infinitive, as in (7a), followed by ń (a form resembling a complementiser (otherwise) restricted to relativising on definite

\footnotetext{
${ }^{13}$ It is unclear if the same meaning is possible without the adverbial phrase.

${ }^{14}$ It is currently unclear if event duration should also be included here, although this appears to be a secondary interpretation allied to iteration/frequency.

${ }^{15}$ We suspect that the subject is definite because the behaviour of a specific referent is being compared to a norm in terms of its behaviour, and it would not make sense to predicate about a non-specific referent in this way because a non-specific referent's behaviour would be characterised as the same as the norm.
} 
nouns). ${ }^{16}$ Note that vowel-initial verb stems form their infinitive with the prefix $k$ - as illustrated in (5) and (7c), but all other infinitives are identical to the third person form of a finite stem, as in (7a-b). When this construction is used with transitive verbs, as in (7c), the direct object of the verb (in this case kàsà 'alcoholic drink') may follow the $\mathrm{CH}$, the CD, or, less commonly, both (Keegan 1997: 151). ${ }^{17}$

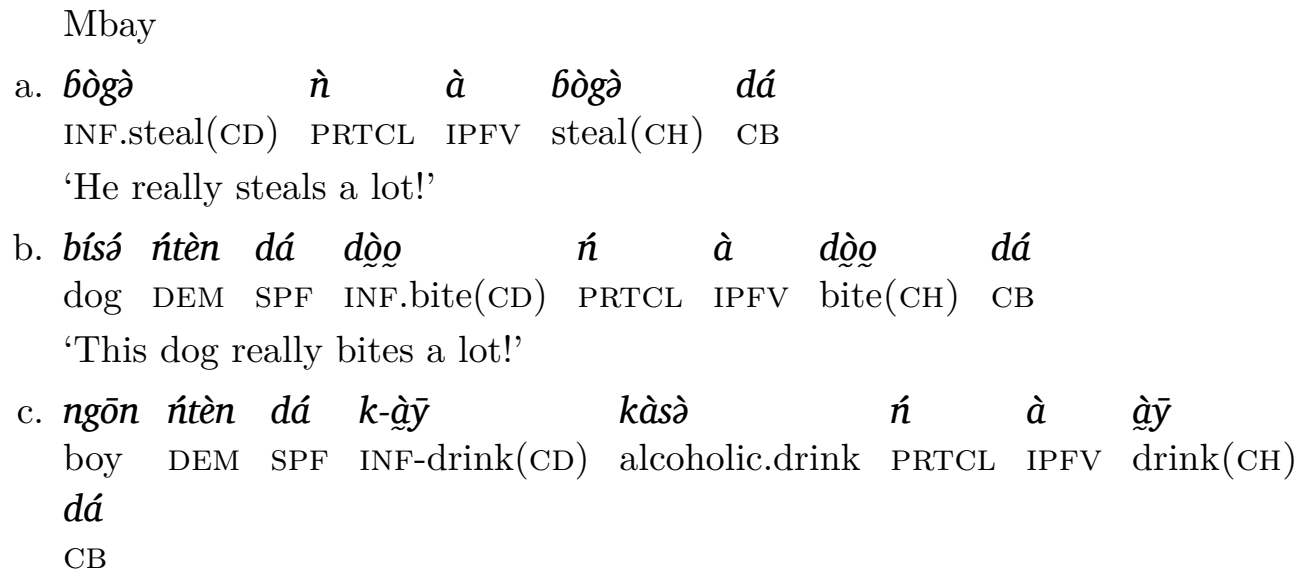

The same structure can be used with predicates encoding gradable properties, where the subject referent's proclivity for that property is judged to be at a high point relative to a contextually defined norm (i.e. a standard of comparison) on a scale associated with that property (see Kennedy \& McNally 2005 for discussion of the semantics of gradable predicates). This is exemplified in (8). ${ }^{18}$ The fact that the lexical head of the predicate (i.e. the $\mathrm{CH}$ ) in (7) is preceded by the imperfective particle helps to identify a finiteness asymmetry between the $\mathrm{CH}$ and CD. However, there is no such indicator of finiteness in (8), and the infinitival form of the property predicate is morphologically identical to the lexical head of the clause. The $\mathrm{CH}$ and $\mathrm{CD}$ in this construction are distinguished through analogy to those in (7).

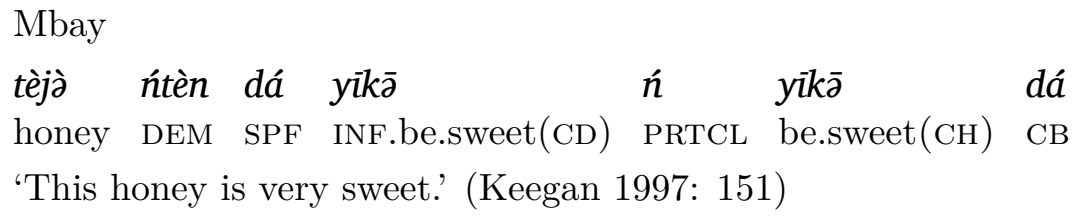

\footnotetext{
${ }^{16}$ Relative clauses in Mbay follow the noun they relativise on (Keegan 1997: 120). If $\dot{n}$ were truly a relativiser, these examples would indicate that the cognate infinitive is relativised on in (7a-b), but a regular noun is relativised on in (7c). This points to an analysis of $n$ in these structures in which it is not a complementiser. It is therefore glossed as PRTCL to avoid this unintended interpretation.

${ }^{17}$ Similar variation in the placement of direct objects is attested in Gidar (Frajzyngier 2008: 373-374).

${ }^{18}$ Note that when property predicates in Mbay occur with the imperfective auxiliary à, there is an inchoative reading (Keegan 1997: 75).
} 
Note that the semantic scale relevant for (8) does not concern the frequent iteration of a state (e.g. 'Honey is often sweet'), but rather the subject referent's relative proclivity to have a property. We use the term proclivity to characterise the relation between a referent and its (relative) inclination or tendency toward a point on a semantic scale representing a gradable property. This is schematised in Figure 2, where the horizontal line of the scale represents the dimension of linear extent. For (8), the dimension of the scale is 'sweetness'.

Figure 2: Semantic scale for property proclivity

REFERENCED HIGH POINT ON A SCALE

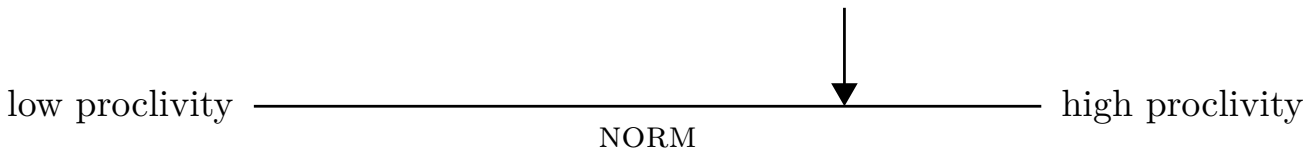

In a similar example comprising a property predicate and non-animate subject from Lango (Nilotic; Uganda), the CHDC indicates a high point on a scale of property proclivity denoted by the predicate, as illustrated by the contrast between (9a) and (9b).

(9)

Lango

a. cèmmì ràc

food.DEM be.bad.HAB

'This food is bad.'

b. cèmmì ràc à-ràc-âa

food.DEM be.bad.HAB(CH) GER-be.bad-GER(CD)

'This food is really bad.' (Noonan 1992: 176)

Further evidence in support of this scalar analysis can be seen in the use of predicative nouns in Zuaran Berber (Berber; Libya). ${ }^{19}$ For instance, in (10), the CD díbSad is used to indicate what Mitchell (2009: 142) refers to as "reinforcement". More specifically, we argue that the $\mathrm{CD}$ is used to indicate high proclivity for a gradable property relative to a norm.

Zuaran Berber

$w$-tə-bYíd-̌̌

d-íb̧ad

NEG-3SG.FEM-be.far.NEG-NEG(CH) PRED-far(CD)

'It's not terribly far.' [but the twists in the road are tiring] (Mitchell 2009: 140)

Note that the use of negation in (10) does not reverse the scale (i.e. it does not indicate a low point on the scale relative to a norm), only the truth-value of the proposition.

\footnotetext{
${ }^{19}$ We are grateful to Lameen Souag for providing suitable glosses for this example. See Mitchell (2009: 140-142) for further examples.
} 
Despite the difference in the outcomes of the use of CDs with event and property predicates, the CHDC is used to indicate a high point on a scale relative to a norm in each case. The principle difference between them is that events - which lack inherent gradability - are placed on an ordered scale, characterised by degree of frequency or iteration, while the scale related to properties is constrained by the semantics of the $\mathrm{CH}$. As with the quantification of events into iterated performance units, discussed in §3.1, these CHDCs are used to indicate a type of quantification related to the gradability of the property itself.

\subsection{Scalar attainment of a goal}

Pluractional semantics associated with CD formations are found in a number of languages across Africa, but they are not always associated with scales of iteration, frequency or property proclivity. Sometimes CDs are used to indicate the degree to which an event is successfully realised. We refer to this as SCALAR ATTAINMENT because the semantics of the predicate require the interpretation of a scale; the dimension of this scale is determined by the conventionalised goals (i.e. potential attainment) linked to the lexical semantics of the $\mathrm{CH}$. We assume that the norm on the scale is contextually determined, and that the typical goals of verbs are conventionalised within individual languages. ${ }^{20}$

Indicating scalar attainment of a goal is one of the functions of the maf'uul mutlaq "cognate accusative" in Classical Arabic (Semitic). In (11) the CD of darabtu 'hit' behaves like a regular transitive object in some sense in that it takes object morphology, here Accusative case. However, there is also verbal agreement with the "real" patient-like object, in this case a third-person singular masculine referent, indicated by the suffix -hu. The clause in (11) reports the speaker's perceived success in attaining the goal of the CH: the $\mathrm{CD}$ indicates a high point on a scale of force from lightly touching to hitting with considerable force. Note that there is no adjective, adverb or similar modifier indicating the force of the hitting event.

$$
\begin{aligned}
& \text { Classical Arabic } \\
& \text { darabtu-hu darban } \\
& \text { hit.PFV.1SG-3SG.MASC.OBJ(CH) hit.ACC(CD) } \\
& \text { 'I hit him hard.' (Versteegh 2001: 78) }
\end{aligned}
$$

In this instance, the construction featuring the CD does not refer to an iterated or frequently iterated event, but rather refers to a relative high-point on a scale of attainment related to a conventionalised goal of the event. This could, of course, also be characterised in terms of intensity, but a scalar dimension of intensity cannot be interpreted without reference to the goal of each $\mathrm{CH}$. Evidence for this view comes from the fact that the semantic dimension of the scale differs depending on the semantics of the $\mathrm{CH}$

\footnotetext{
${ }^{20}$ By way of example, consider the different interpretations the Classical Arabic example in (11) and the Ewe example with a verb denoting a similar event in (19), §4.1.
} 
itself. This is demonstrated by the Kana (Cross River; Nigeria) constructions in (12). In these examples the "intensive" readings reflect the successful attainment of the normal goals of the event depicted by the verb.

For instance, the conventionalised goal of running is to move quickly, so degree of attainment is measured through the speed of movement (12a). ${ }^{21}$ Similarly, the conventionalised goal of sleeping is to rest, so degree of attainment is measured by the depth or perceived success of the sleep, as indicated by the translation in (12b). The dimension of the scale is determined by the semantics of the $\mathrm{CH}$; the use of the CD in (12b) does not mean that sleeping was fast, but rather deep or especially restful. Finally, the goals of crying are to express pain, make noise or gain attention, so the attainment here concerns the agent's efficacy in relation to these specific goals, as in (12c).

Kana (Ikoro 1996: 234)
a. lé āā-wéé téērā téē
Le PROG-PST $\operatorname{run}(\mathrm{CH}) \operatorname{run}(\mathrm{CD})$
'Le was running (very fast).'
b. lé āā-wéé dá dáá
'Le was sleeping (very well).'
Le PROG-PST $\operatorname{sleep}(\mathrm{CH})$ sleep(CD)
c. lé āā tó tó
Le PROG $\operatorname{cry}(\mathrm{CH}) \quad \operatorname{cry}(\mathrm{CD})$

'Le is (really) crying.' (Ikoro 1996: 234)

Once again, the semantics of these constructions can be schematised using a scale, as in Figure 3. Here, the dimension of linear extent concerns the degree to which the conventionalised event goals were attained.

Figure 3: Semantic scale for attainment of a goal

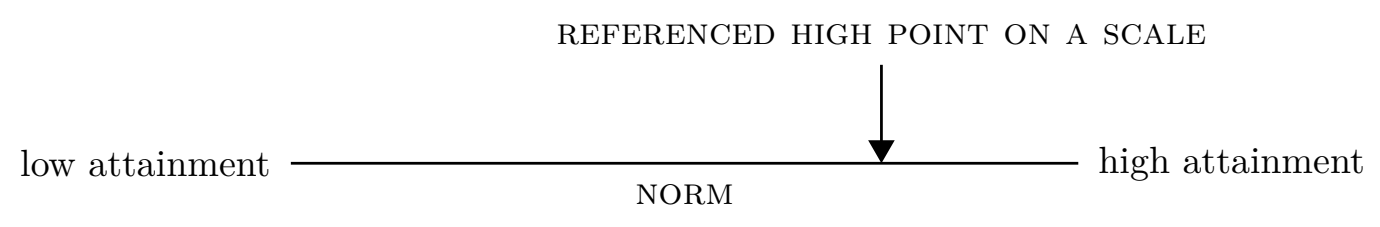

While it might be tempting to analyse these examples in terms of intensity, this would ignore the fact that the interpretation of the scale reflects conventionalised agent-oriented goals of the situation embodied by the lexical head of the predicate.

Further evidence for this viewpoint is provided by examples from Izi (Igboid; Nigeria) where there are CHDCs involving both active and stative verbs. As with the Kana examples in (12), CDs in Izi are used to indicate relative success in attaining the goals

\footnotetext{
${ }^{21}$ Note that this example does not necessarily mean that the subject referent ran for a long period of time, or that the event as a whole was iterated.
} 
of an event. In (13a) the goal of giving is to transfer possession permanently (rather than, say, give away large amounts), while in (13b) the goal of knowing is the pursuit of having plentiful and accurate knowledge. The concept of intensity is not very useful in accounting for the meaning of (13a). ${ }^{22}$

$$
\text { Izi }
$$

a. ọ́ nụ̀rù̀ mụ ùwé ầ-nứnụ

3SG.SBJ give( $\mathrm{CH})$ 1SG.OBJ clothes GER-give(CD)

'He gave me clothes for me to keep.'

$$
\begin{array}{llll}
\text { b. } \begin{array}{l}
\text { ó } \\
\text { 3SG.SBJ }
\end{array} & \text { knàrụ } & \text { k̀yà } & \text { à-máàrù̀ } \\
& \text { 3SG.OBJ } & \text { GER-know(CD) }
\end{array}
$$

'He really knows him well.' (Meier et al. 1975: 160)

While the examples presented above are somewhat different from the iterative examples in $§ 3.1$, the scalar analysis links them to the intermediary examples in 3.2 , suggesting a potential diachronic dimension to their relationship.

\subsection{Endpoint attainment of a goal}

While the evidence from languages with CHDCs indicating scalar attainment of a goal referencing a highpoint on a scale relative to a norm, a less common type of construction references the endpoint of a scale. In Kanakuru (West Chadic; Nigeria), the scalar interpretation of a CHDC is taken to its logical extreme; use of a CD indicates that the event described by the predicate was performed so successfully, it was done so to completion, as in (14). ${ }^{23}$

Kanakuru (Newman 1974: 80)
a. nà
$g a$
re
$g a-m a$
1SG.PFV prevent(CH) 3SG.FEM.OBJ prevent-DEP(CD)
'I prevented her completely.'
b. arai à pule-ni pul-ma
soup.DEF 3SG.PFV boil-VENT(CH) boil-DEP(CD)
'The soup boiled away.'

\footnotetext{
${ }^{22} \mathrm{CDs}$ in Izi used for expressing a high point relative to a norm on a scale of attainment of goal have the morphological makeup of gerunds (Meier et al. 1975: 66). The gerund form of the verb màru bears a prefix $\grave{E}$ - harmonic with the stem (Meier et al. 1975: 66) and a distinct tonal pattern. In (13a) the gerund is marked by HL contour tone (and possibly vowel lengthening in deliberate speech) (Meier et al. 1975: 66). Constructions in which a CD functioning as a direct object (i.e. a cognate object) of a $\mathrm{CH}$ are also found in Izi and discussed by (Meier et al. 1975: 186, 232-3) under the label 'verbbound nominals'. They differ from gerunds in that the nominal prefix of such forms may be a homorganic nasal or any ATR harmonic vowel (Meier et al. 1975: 232-3, 240).

${ }^{23}$ Arguably, (13a) is a similar example.
} 


\section{c. à núm gókòi nùm-má \\ 3SG.PFV close $(\mathrm{CH})$ gate.DEF close-DEP(CD)}

'He closed the gate shut.' (Newman 1974: 80)

The type of CHDC exemplified in (14) contrasts with an alternative construction in Kanakuru involving a totality extension, such that they are mutually exclusive. Newman (1974: 80) explains that in the CHDC, the 'emphasis is on the action of the verb'; when the verb receives the totality extension, the 'emphasis is on the impact of the verb on the object (or subject in the case of intransitive sentences)'. Combining the two strategies is ungrammatical. It remains open to what extent lexical semantic classes affect the interpretation of the CHDC in Kanakuru, due to the limited data available. Similarly, the extent to which CHDCs are employed cross-linguistically to indicate the logical completion of an event is currently unclear, but the connection between the uses of CDs to indicate a high point on a scale related to the attainment of a goal and those used to indicate the logical endpoint on a scale of completion of a goal seems to be a highly plausible one.

\subsection{Summary}

The iconic use of a CD within a clause expressing event iteration (§3.1), event frequency or property proclivity (§3.2) involves the individuation and quantification of events and the quantification of gradable properties. Iterated events quantify repeated performance units, while frequently occurring events are quantified in terms of (i) the repetition of individuated performance units and (ii) a gradable scale with a dimension that captures the degree of frequency over time relative to a norm. Unlike events, gradable properties are inherently predisposed to a scalar analysis relative to a norm, and therefore do not require individuation. With this in mind, we propose that the use of scales in the interpretation of CHDCs is an important part of their pluractional semantics.

In some instances of pluractionality, there is no indication of iteration, but the events are quantified in terms of the degree to which the conventionalised event goals are met (§3.3). A logical endpoint appears to be referenced by CHDCs in some languages (§3.4). Here the relevant scale is interpreted aspectually and the presence of the CD identifies that this aspectual modification forms the information focus of the clause.

\section{Focus and new information}

Cognate dependents are commonly employed for focus manipulation in African languages, being particularly prevalent in the Niger-Congo and Afro-Asiatic phyla. In this section, we outline the ways in which CDs are employed to signal differences in focus in a range of different languages. We argue that focus in CHDCs is simultaneously indicated in two ways: (i) iconically, by virtue of (near) "repetition" of the head of the predicate (i.e. in the form of a CD), and (ii) structurally by virtue of the CD occurring in a syntactic position otherwise associated with discourse prominence. In some instances, CDs are also accompanied by focus particles or focal morphology. 
Broadly conceived, focus concerns 'that part of the clause that provides the most relevant or most salient information in a given discourse situation' (Aboh et al. 2007: 1). It is widely acknowledged that discourse felicitous utterances (normally) require a successful information focus (Bolinger 1965, Halliday 1967, Rooth 1992, Lambrecht 1994, É Kiss 1998, Polinsky 1999, Goldberg \& Ackerman 2001), essentially because the main function of language is the exchange of information and utterances are structured in order to optimise this exchange (cf. Dalrymple \& Nikolaeva 2011). Focus refers to the informative part of a proposition, and thus contrasts with the GROUND: content that is presupposed, given or non-informative. Because focus concerns the way in which an assertion differs from its presupposition, information that is in focus is typically new or contrasted with information in the proceeding or subsequent discourse.

Focus marking strategies can be typologised in terms of their formal characteristics (i.e. phonological, morphological or syntactic form), and in terms of the aspect of meaning that is highlighted as informative (Matić \& Nikolaeva 2009). ${ }^{24}$ Studies of focus in African languages exemplifying different strategies can be found in Fiedler \& Schwarz (2006), Fiedler \& Schwarz (2010), Aboh et al. (2007), Ermisch (2009) and Ameka (2010). The discussion that follows is structured according to the information-structural functions of the strategies used. We argue that CDs are employed for at least three focus related goals in African languages. We first exemplify the use of CHDCs to indicate verb or predicate focus $(\S 4.1)$, before examining those used to mark polarity focus $(\S 4.2)$ and exclusive focus $(\S 4.3)$. Interim conclusions are drawn in $\S 4.4$.

\subsection{Verb focus and predicate focus}

Verb focus strategies identify the lexical content of the verb as new information, while in predicate focus strategies the focus domain covers the lexical verb and other nonverbal elements that form part of the predicate. The use of CDs in verb and predicate focus constructions is well known in the languages of West Africa, particularly in cases where a deverbal noun or "verbal copy" occurs at the left periphery of a clause (e.g. Ameka 2010, Kandybowicz 2008). In this section, we examine the use of CDs for this purpose in the Moru-Ma'di, Kwa, Cross-River and Biu-Mandara genera, exemplifying focus strategies where CDs play a crucial role. We begin with discussion of constructions that involve focus marking through the presence of a tonal alternation, before examining those strategies that employ focus particles and structures where the primary indicator

\footnotetext{
${ }^{24}$ Syntactic dislocation, morphological focus markers, aspectual modification, and tone are each examples of formal strategies utilised to indicate focus in African languages (Aboh et al. 2007: 5-6). Intonational pitch-accents are a further focus strategy attested elsewhere (Selkirk 1984, see also Mycock 2007). Repetition is a prominent, localised cues that, at face value, appears to be employed as a technique to draw a hearer's attention to a particularly salient part of an utterance, and in this sense it parallels other common means to mark focus (e.g. prosodic prominence, syntactic prominence, etc.). A pragmatic-iconic position of this kind is taken by Hutchinson (2000: 584) in his overview of predicate focus marking in African languages. Making reference to cognate objects in focus constructions he asserts: 'What better way for a language to emphasise or focus the achievement of the action of the verb than to essentially nominalise that action as an accomplishment which then functions as the complement of the action itself'.
} 
of focus is the syntactic structure used.

In Ma'di (Moru-Ma'di; Uganda, Sudan), verb focus constructions require a CD. ${ }^{25}$ For instance, in (15a) a zero-derived CD of the high tone verb esú 'find' occurs in a position after the object noun phrase gàlámù $d \hat{t}$ 'this pen' and is followed by a low tone indicating focus. In similar constructions with verbs ending in a mid-tone, the tonal focus marker replaces the mid-tone on the CD (15b-c) ${ }^{26}$

Ma'di (Blackings \& Fabb 2003: 596-7)

a. ópt́ ēsú gàlámò dî ēsû

Opi find $(\mathrm{CH})$ pen DEM find.FOC $(\mathrm{CD})$

'Opi found this pen (i.e. he didn't buy it or steal it).'

b. ćrúá ìvvū-ā mvù

medicine NPST.drink-OBJ(CH) drink.FOC(CD)

'Medicines are to be drunk.'

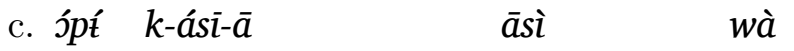

Opi 3-NPST.fry-OBJ(CH) fry.FOC(CD) POSB

'Opi can fry it.' (Blackings \& Fabb 2003: 596-7)

Crucially, the CD must be present for verb focus to be indicated. In each of these examples, the $\mathrm{CD}$ is less finite than the $\mathrm{CH}$. This is clear from the asymmetries in the inflection in (15b-c). In (15a) the verb appears in the default past tense form and therefore bears a greater phonological similarity to its CD.

A similar situation holds in Gwari (Nupoid; Nigeria), where a post-verbal CD occurs when a $\mathrm{CH}$ is contrastively focused. Note that the $\mathrm{CD}$ occurs after the CH's direct object shnamá 'yam' and is followed by the focus particle $n u$, as in (16). ${ }^{27}$

$$
\begin{aligned}
& \text { Gwari } \\
& \text { èbi sĩ shnamá si si } \quad n u \quad l o \\
& \text { child buy(CD) yam RED buy }(\mathrm{CH}) \text { FOC PROG }
\end{aligned}
$$

'The child is buying yams (not selling them).' (Hyman \& Magaji 1970: 122)

While CDs may be in the same verb phrase as their $\mathrm{CH}$, the use of a CD in the left periphery to signify focus is a frequently observed scenario, attested across much of West Africa and beyond. ${ }^{28}$ Typically a deverbal noun, or non-finite form of the verb is found in a left peripheral position associated with focus. In Nupe (Nupoid; Nigeria),

\footnotetext{
${ }^{25}$ Evidence provided by Ma'di (Blackings \& Fabb 2003: 600) for links between verb focus and exclusive focus will be discussed in $§ 4.3$.

${ }^{26}$ The modal particle wà is always clause final, as in $(15 \mathrm{c})$, and therefore does not indicate anything about the internal constituency of the clause, nor pose any problems for the analysis adopted here.

${ }^{27} \mathrm{We}$ are grateful to an anonymous reviewer for drawing our attention to this example.

${ }^{28}$ Predicate cleft constructions involving CDs (especially infinitives) are common in many welldescribed languages originating in Europe and the Middle East. Kandybowicz (2008: 91) cites examples from Brazilian Portuguese, Spanish, Russian, Yiddish, Hungarian, Turkish and Hebrew.
} 
CDs are formed through reduplication of the verb stem including a vowel modification of the reduplicant, as in (17a). ${ }^{29}$ Here, the CD occurs in the left periphery, with a focus particle in clause final position. Without the $\mathrm{CD}$ and focus particle, there is no contrastive focus meaning, as in (17b).

$$
\text { Nupe }
$$

a. Pi pa Musa à pa eci o RED pound(CD) Musa FUT pound(CH) yam FOC

'It is pounding that Musa will do to a yam (as opposed to to say, boiling).'

b. Musa à pa eci

Musa FUT pound yam

'Musa will pound a yam.' (Kandybowicz 2008: 92)

In Akan (Kwa; Ghana) predicate focus constructions, a CD is found in a left peripheral position together with a focus particle, as illustrated in (18). Note that, in Akan, the focus particle directly follows the CD, while in Nupe, the focus particle occurs in clause final position.

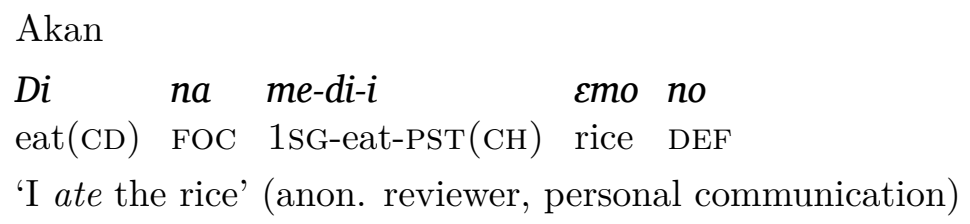

The CD di in (18) does not have the characteristics of a regular Akan deverbal noun since the nominalised form of the verb di 'eat' is adidie (where, in addition to the noun prefix $\boldsymbol{a}$-, the reduplicated stem takes a suffix -e). Nevertheless, there is still an asymmetry in finiteness between the $\mathrm{CH}$ and the $\mathrm{CD}$ in the left periphery. This uncontroversially demonstrates that several lexically related forms may exist concurrently within the same language.

The following Ewe (Gbe; Ghana) example also has a CD in the left periphery of the clause, followed by the argument (i.e. term) focus marker (y)e. In Ewe, this is the position associated with the focus of arguments and adjuncts of the clause, including subjects, objects, adverbs and prepositional phrases (Ameka 2010: 150-155).

$$
\begin{array}{lll}
\text { Ewe } & & \\
\text { fo } \sim f o-e ́ & \text { wo-fo } & \text { devi-a } \\
\text { RED } \sim \text { hit-AFOC(CD) } & \text { 3SG-hit (CH) } & \text { child-DEF }
\end{array}
$$

'He gave the child a thorough beating.' (Ameka 2010: 159)

\footnotetext{
${ }^{29}$ Reduplication is indicated with a tilde, following the conventions of the Leipzig Glossing Rules, available at: http://www.eva.mpg.de/lingua/resources/glossing-rules.
} 
Ameka (2010: 159) argues that the use of the CD in (19) 'signals the intense and exhaustive nature of the action of beating'. Examples of this kind give an insight into the links between the use of the CDs in focus constructions and the scalar semantics discussed in §3. In (19), the CD is found in a position associated with the focal prominence (i.e. the left periphery), but the information focus of the clause concerns not only the lexical content of the verb, but also the degree to which the goal of the verb were achieved, i.e., iconically motivated focus on scalar attainment of a goal, discussed in $§ 3.3$.

The use of CDs to signal verb or predicate focus appears to be particularly common in Biu-Mandara languages of the Nigeria-Cameroon border area including Guduf, Lamang, Podoko (Wolff 2003), Gidar (Frajzyngier 2008) and Hdi (Frajzyngier \& Shay 2002). For instance, in Gidar predicate focus constructions, a cognate infinitive form of the verb is obligatorily employed. Infinitives in Gidar are formed from a verbal root through the addition of an initial schwa, and a final vowel that undergoes vowel harmony with preceding vowel in the stem. If their subject is second-person or third-person plural, infinitives can inflect for the person, number and gender of their object, the number of their subject and for a totality extension (Frajzyngier 2008: 373-374), as in (20), but they do not appear to inflect more generally for tense or aspect. ${ }^{30}$

$$
\begin{array}{lll}
\text { Gidar } & & \\
\text { á-gù-má-n } & \text { à-dà } & \text { gà-má-nì } \\
\text { INF-wait.TOT-1PL.OBJ-PL(CD) } & \text { 3-DEP.PROG } & \text { wait-1PL.OBJ-PL.SBJ(CH) }
\end{array}
$$

'They are awaiting us.' (Frajzyngier 2008: 374)

In (20), the fronted infinitive inflects for agreement with the person and number of the object and for the number of the subject; the person of the subject is marked on the progressive aspect auxiliary. The lexical head of the predicate must occur in its root (rather than infinitive) form in Dependent Progressive constructions like (20). According to Frajzyngier (2008: 252), the Dependent Progressive is 'the main means of coding a clause as requiring another proposition for its proper interpretation' and it 'is used in comments on the predicate in focus, resembling the tautological infinitive of Semitic and Indo-European languages'. The example in (20) differs from the other examples discussed in this section as there is no dedicated focus particle or morphological exponent of focus in the clause.

In Hdi (Biu-Mandara; Nigeria, Cameroon), CHDCs are also used for verb or predicate focus without additional focus marking (Frajzyngier \& Shay 2002: 161). This is can be illustrated with the adversative construction in (21), in which the verb is focused in preparation for the cancellation of the ensuing expectations by the second clause.

\footnotetext{
${ }^{30}$ Frajzyngier (2008: 193-195) asserts that the use of the totality extension on transitive verbs indicates that the entire object referent/all referents of the object have been affected. It is surprising in the current account that the totality extension is not found on the lexical verb as well as the infinitive, but Gidar has a complex morphophonology and Frajzyngier (2008) is not consistent in identifying this affix/stem change across examples. This issue therefore remains unresolved for the time being.
} 
$(21)$

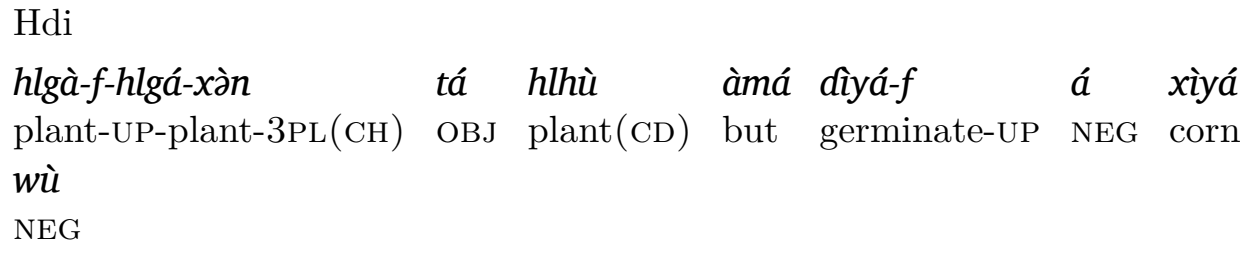

'They planted, but the corn did not germinate.' (Frajzyngier \& Shay 2002: 162)

In this example, the verb hlgá 'plant' is reduplicated to signal Perfective aspect. The upward movement extension $f$ (glossed as UP) is obligatory with this verb (Frajzyngier \& Shay 2002: 263). The CD hlhù is marked by the object marker tá because it is separated from the verb by the subject suffix -xàn. (Frajzyngier \& Shay 2002: 131). Crucially, the $\mathrm{CD}$ occupies the position normally associated with an object in a regular transitive clause (Frajzyngier \& Shay 2002: 5) and shifts focus onto the verb.

Similar examples are found in Suundi (Bantoid; Congo), as in (22). Hadermann (1996: 162-163) proposes that, in Suundi, "la structure "infinitifX + verbe conjuguéX" est à l'origine une structure emphatique qui avait pour but de souligner le procès exprimé par le verbe conjugué" [the structure "infinitivex + finite verbx" originates from an emphatic structure that has the aim of stressing the process expressed by the finite verb]. The difference in meaning between (22a) and (22b) therefore concerns the information focus of the clause.

Suundi

a. ndyèkátángà

1SG.PROG.read

'Je vais lire.' [I am going to read.]

b. kùtángà ndyèkátángà

read.INF(CD) 1sG.PROG.read

'Je vais lire.' [I am going to read.] (Hadermann 1996: 161)

Cross-linguistic observations on the relationship between non-subject dependents cognate with their head and verb/predicate focus marking were noted at least as early as Faraclas \& Williamson (1984). Variation in focus marking deployed in the Upper-Cross languages of the Cross River genus indicates that focus marking strategies synchronically resembling reduplication, diachronically derive from CHDCs. For instance, in Lokạa (Cross River; Nigeria), there is synchronic variation between (i) the use of a $\mathrm{CH}$ and a CD as separate words in a structure that indicates verb focus, and (ii) a fused form resembling reduplication, used for the same grammatical function. Faraclas \& Williamson (1984: 13) provide an example in which an inflected verb form followed by a CD (m̀kpéná ùkpéná) alternates with a fused form consisting of material from the $\mathrm{CH}$ and CD ( m̀kpékpéná). An unglossed example from Lokạa is provided in (23). The use of a similar construction to express contrastive verb focus are also reported for the closely related language Kohumono (Cross River; Nigeria) (Faraclas \& Williamson 1984: 13). 


\section{Lokạa \\ Ǹwènè ńwùňwù, m̀-kpéná ù-kpéná}

'I wasn't stealing the book, I was only looking at it.' (Faraclas \& Williamson 1984: 13)

Elsewhere in Upper Cross, fusion between the $\mathrm{CH}$ and its dependent is argued to be further advanced, such that verb focus always resembles reduplication and the presence of a non-fused dependent is no longer attested with this meaning. For instance, in Obolo (Cross River; Nigeria), verb focus is achieved through verbal reduplication (Faraclas 1989: 393) as in (24). In such cases, the reduplicated segment consists of copy of the initial consonant of the stem followed by a copy of the vowel of the first syllable of the stem (unless it is $i$ or $u$ in which case the vowel in the reduplicated segment is lowered to $\boldsymbol{e}$ or $\boldsymbol{o}$ respectively) (Faraclas 1984: 60). All reduplicated segments contain a short vowel, even if the stem vowel is long, indicating that the reduplication process acts on the mora, not the syllable.

$$
\begin{aligned}
& \text { Obolo } \\
& \text { ǹ-gêe } \sim \text { ì } \quad \text { ikpá } \\
& \text { 1SG-RED } \sim \text { write.PST letter } \\
& \text { 'I wrote (a letter) (instead of giving a verbal message).' (Faraclas 1989: 393) }
\end{aligned}
$$

Other Niger-Congo languages hypothesised to have developed reduplication as a verb focus or 'emphasis' strategy through fusion between a verb cognate with its dependent include Jukun (Jukunoid), Gwari and Gade (Nupoid), Efik, Ibibio and Anaang (Cross River) (Faraclas \& Williamson 1984: 2, 13-14). ${ }^{31}$

\subsection{Polarity focus}

Polarity is focused when an assertion differs from its presupposition in terms of 'truthvalidity' and the rest of the information conveyed is discourse old. Following Zimmermann \& Hole (2008), Matić \& Nikolaeva (2009) define polarity focus as 'focus on the truth value of the proposition in the reference $(\approx$ actual $)$ world in comparison to other possible worlds' ${ }^{32}$

Essentially, polarity focus indicates something about the speakers' commitment to the truthfulness of the proposition expressed and therefore differs from predicate focus (where there is focus on a VP) or verb focus (where there is focus on the lexical content of the verb). ${ }^{33}$ In some African languages, polarity focus is expressed through the use of a

\footnotetext{
${ }^{31}$ Of these languages, the only examples provided are of postposed dependents in Jukun and Gwari.

${ }^{32}$ Polarity here does not refer to whether the clause is affirmative or negative. The examples provided are all from affirmatives. It remains to be seen whether CDs are used in their corresponding negatives.

${ }^{33}$ Polarity focus is also known as "verum focus" (e.g. Romero \& Han 2004). In literature on African languages it is also frequently referred to as "auxiliary focus" following the work of Hyman \& Watters (1984). Since this label does not accurately capture the domain of focus, this term is not used here.
} 
CD that has properties of an infinitive, gerund or deverbal noun. In such cases, a CHDC highlights that the speaker agrees or disagrees with a discourse salient proposition. ${ }^{34}$

In the İgboứzọ̀ dialect of Igbo (Igboid; Nigeria), polarity focus is achieved through the use of a post-verbal CD, as in (25a). This example contrasts with the non-focussed version in $(25 \mathrm{~b})$, which lacks a CD.
İgboứzọ̀ Igbo
a. Ó zà ứnọ́ à a-zaá
3SG sweep $(\mathrm{CH})$ house DEM NMLZR-Sweep (CD)
'S/he really swept this house.'
$\begin{array}{llll}\text { b. } & \text { zà } & \text { ụ́nọ́ } & \grave{a} \\ 3 \mathrm{SG} & \text { sweep } & \text { house } & \text { DEM }\end{array}$
'S/he swept this house.' (Williamson 1986: 10-11, Urua 1997: 196)

In Akye (Kwa, Côte d'Ivoire), polarity focus is indicated by the presence of a CD in the left periphery of the clause, as in (26). This resembles other focus structures from Kwa languages in which the focussed element occurs in a left peripheral position. Bogny (2005) claims that the examples in (26) represent instances of verb copying. He proposes that with disyllabic verbs, it is only the first syllable of a verb that is copied as in (26a); if a verb is mono-syllabic, the whole verb is copied, as in (26b).
Akye
a. bō $\quad m \bar{a}$ àdú bōkà $m \underline{\sim}$
help(CD) FOC Adu help.PST(CH) 1SG
'Adu truly helped me.'

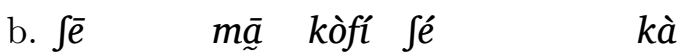
eat(CD) FOC Kofi eat.PST(CH) thing
'Kofi ate truly.' (Bogny 2005: 29)

We hypothesise that Akye polarity focus constructions do not involve copying, but licensing of a $\mathrm{CD}$, in line with similar evidence from related languages. The evidence presented by Bogny (2005) indicates that disyllabic verbs derive historically from the fusion of monosyllabic verbs and their complement, e.g. $b \bar{o}+k \grave{a}$, suggesting that CDs may have been (zero) derived before fusion occurred. Furthermore, even monosyllabic verbs such as fé 'eat' do not always have identical tonal forms to the those found in the left periphery of polarity focus constructions, demonstrating that the CD in focus position is only superficially a(n identical) copy of the $\mathrm{CH}$.

The appropriate use of a CHDC for indicating polarity focus may be determined by pragmatic properties of the wider discourse. In Lango (Western Nilotic; Uganda),

\footnotetext{
${ }^{34}$ In the examples that follow, the English translations provided in the various source materials aim to reflect the fact that the speaker is committed to the truth of the proposition. Since English does not have a comparable syntactic construction, polarity focus is generally reflected by the use of the adverbs such as really, truly, indeed and assertive uses of the auxiliary do.
} 
a CHDC is often used when the sentence expresses opposition to a contrary opinion (Noonan 1992: 175), as in (27).

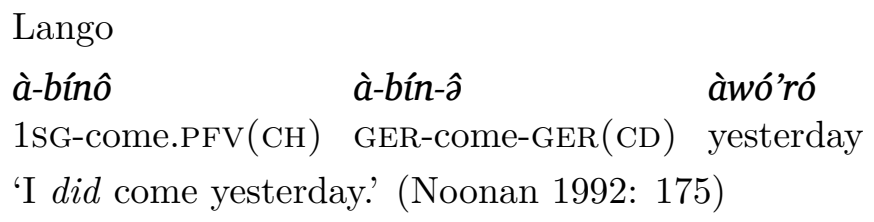

Elsewhere, in Mina (Biu-Mandara; Cameroon), a CHDC is used to confirm an interlocutor's presupposition, where a more elaborate explanation is due to follow (Frajzyngier et al. 2005: 169). In (28), the cognate form misil is introduced by a preposition $\boldsymbol{i}$ (like some other types of adjunct in the language); the form of the CD is identical to that of the root of the $\mathrm{CH}$, which is inflected with a suffix indicating a goal orientation (i.e. that an event happened at a specific place):

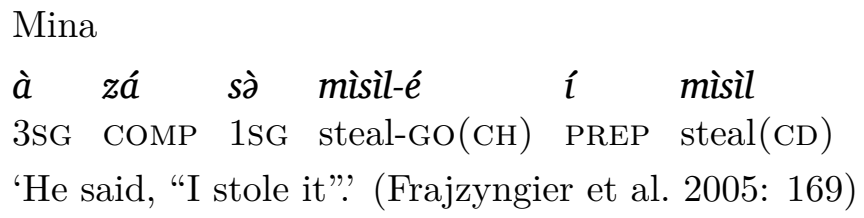

This form is described as a cognate adverb by Frajzyngier et al. (2005: 169), presumably because they believe it modifies the event. However, if their analysis of the conditions for its use are correct, then it appears to be used to assert the validity of a presupposition - and this must be the informative part of the utterance. Matic \& Nikolaeva (2009) demonstrate that polarity focus and predicate focus use the same syntactic structure, morphological strategy and/or prosody in a wide range of languages. However, polarity focus constructions may also have a LOCAL STRATEGY, i.e. a focus strategy that is distinct from that used for other focus types within the language, including those that have the distinguishing characteristics of CHDCs (as outlined in §2). The fact that CHDCs are found to mark verb focus/predicate focus or polarity focus in different languages is therefore unsurprising, although reliable evidence for cases where CHDCs are used for both polarity focus and verb/predicate focus synchronically within the same language are currently unavailable.

\subsection{Exclusive focus}

CHDCs used to indicate verb/predicate focus or polarity focus give information-structural prominence to the predicate or to the relative truthfulness of the proposition expressed. A further type of focus marked by CHDCs, called EXCLUSIVE FOCUs, gives prominence to a sub-domain of predicate semantics by excluding higher-ranked alternatives on an ordered scale. ${ }^{35}$ Exclusive focus is commonly associated with adverbials in European languages (König 1991). In English it is marked by adverbs such as merely, solely, alone,

\footnotetext{
${ }^{35}$ Exclusive focus is a type of restrictive focus (König 1991: 33).
} 
exclusively, simply, etc. Here, we distinguish three different types of exclusive focus expressed using CHDCs in African languages, which have different focus domains. We refer to these subtypes as exclusive purpose focus, exclusive situation focus and exclusive affectee focus.

\subsubsection{Exclusive purpose focus}

In CHDCs indicating EXCLUSIVE PURPOSE FOCUS, the purpose of the event is in focus and alternative purposes are excluded. Such constructions indicate that the subject referent engages in the event expressed by the $\mathrm{CH}$ exclusively to realise the event itself, to the exclusion of any other explicit purpose. For instance, in relevant examples from Sheko (North Omotic; Ethiopia), CHDCs can indicate that the event encoded by the $\mathrm{CH}$ is engaged in by its agent without any other goal in mind, as in (29).

$$
\begin{aligned}
& \text { Sheko } \\
& \text { Context: response to the question 'Where are you going?' } \\
& \text { nat-nâ bóózà } \quad m=\text { bòòs-kì-k-ə } \\
& \text { 1SG-or.Q walk.INF(CD) } 1 \mathrm{SG}=\text { walk-exist-REAL-INDST(CH) } \\
& \text { 'Me? I am just walking/taking a stroll.' (Hellenthal 2010: 174) }
\end{aligned}
$$

Similar examples such as (30) are found in Acholi (Nilotic; Uganda, Sudan). Here the speaker self-reports that speaking took place without an ulterior purpose in mind.

\section{Acholi}

lok moo pe, a-waco a-wac-a

word PRTCL NEG 1SG-Say(CH) GER-say-GER(CD)

'There is nothing, I said it just for saying.' (i.e. for the sake of talking).

(Malandra 1952: 109)

Exclusive purpose focus readings are also found elsewhere in East Africa. In Lango (Nilotic; Uganda), a cognate gerund can be used together with a $\mathrm{CH}$ to indicate that an event being engaged in is done so without any known related purpose or reason. ${ }^{36}$ For instance, in (31), a gerundive form of the verb 'dance' follows the finite verb to indicate 'that the activity so described is simply or merely carried out' (Noonan 1992: 175). ${ }^{37}$

\footnotetext{
${ }^{36}$ Lango gerunds are formed through assigning a high tone to the verb root and affixing $\grave{a}-$ and $-\hat{a}$ to the newly formed stem. Noonan (1992: 283) claims that the gerunds used in these constructions cannot be considered cognate objects on the basis that both transitive and intransitive verbs have cognate forms used in this way.

${ }^{37}$ Note that the use of $j u s t$ in the translation should not be taken to necessarily indicate that the event refers to immediate past events. Rather, just, simply and merely are associated with indicating a lack of explicit purpose or reason in English, with merely also being used to express a low point on the scale.
} 
$(31)$

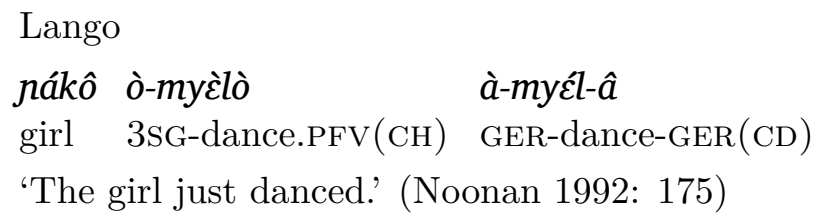

We propose that in a scalar analysis of exclusive purpose focus, potential purposes of an event are ranked on a ordered scale, such that highly ranked alternatives are excluded. This is represented schematically in Figure 4.

Figure 4: Ordered scale for exclusive focus

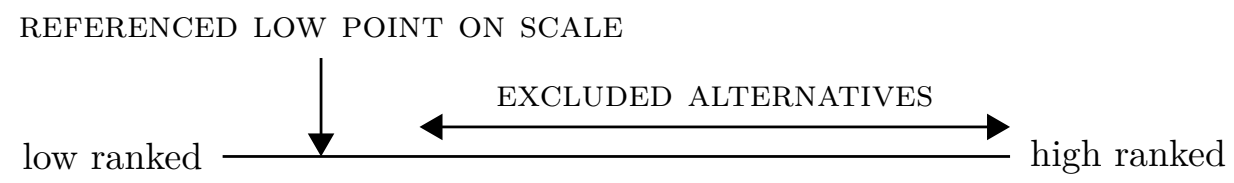

Note that, while different in their interpretation, the scale used in exclusive focus is conceptually similar to the scales required in the interpretation of aspect in $\S 3$.

\subsubsection{Exclusive situation focus}

A further subtype of exclusive focus, namely EXCLUSIVE SITUATION FOCUS, indicates that the situation (i.e. event or state) described by the predicate is in focus, to the explicit exclusion of other (higher-ranked) situations. For instance, Acholi CHDCs can be used to exclude any opposite or alternative meaning to that expressed by the $\mathrm{CH}$ (Savage 1956: 48-49). For instance, in (32), the addressee is engaging in one event (i.e. talking) to the exclusion of others (i.e. going and doing). According to Kitching (1932: 14), such forms (which he describes as reduplicated verbs), 'emphasize the essential idea of the verb, more or less implying the exclusion of some other idea'.

Although the verb forms in (32) and (33) appear to comprise two copies of the verb, Malandra (1952: 109-112) indicates that this is not reduplication, per se, but rather coalescence between an intransitive verb stem (i.e. the $\mathrm{CH}$ ) and a cognate gerund (i.e. a CD) following elision of a verb final vowel (cf. the examples of reduplication in verb focus constructions in (23) and (24)).

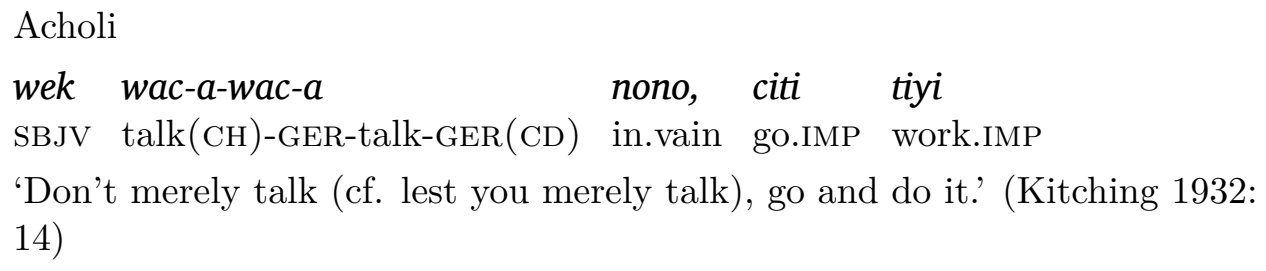

The CHDC in (33) indicates that other types of activity do not contribute to the tiredness experienced by the speaker. Examples like this, where implicatures about other events arise as a result of the restricted focus of the clause, are conceptually similar to 
the examples with exclusive purpose focus, discussed above. It also bears some similarity with verb focus constructions discussed in (§4.1).

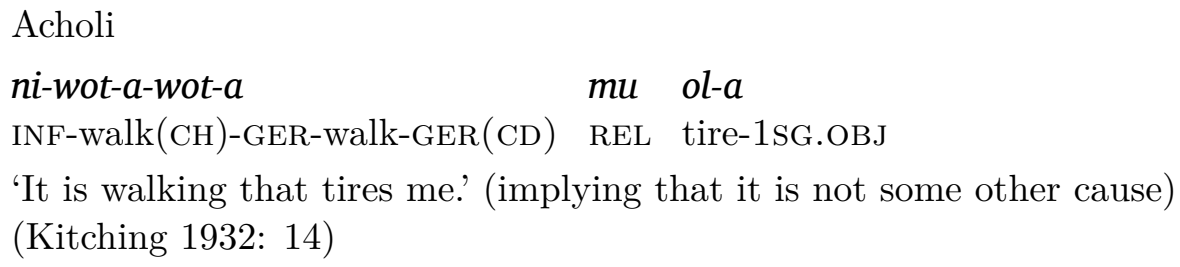

The fact that cognate gerunds in Acholi are used for both exclusive purpose focus and exclusive situation focus supports König's (1991: 31) observation that the formal means of indicating focus and scope must have distinct representation.

Similar exclusive situation focus readings are found with certain CHDCs in Mbay (Bongo-Bagirmi; Chad, Central African Republic), where the CH in a CHDC is followed by a particle $t \bar{a}$ and an infinitive form of the verb to indicate that the activity occurs very commonly, to the exclusion of other activities, as in (34).

$$
\text { Mbay }
$$
a. $\grave{a} \bar{y}$
kàsà
$t \bar{a} \quad k$-ày drink $(\mathrm{CH})$ alcoholic.drink PRTCL INF-drink(CD) 'to do nothing but drink (alcohol)'
b. $\grave{a} \bar{w} \quad m b \bar{a} a$ tā $\quad k$-à $\bar{w}$ go(CH) trip PRTCL INF-go(CD) 'to do nothing but travel'

Structurally similar construction where the $\mathrm{CH}$ denotes a gradable property may evoke a scalar interpretation of the type discussed in §3.2. This is true of Mbay property predicates formed with 'adjectival verbs', as in (35a) and other property predicates formed with $i$ 'be' as in (35b).

$$
\text { Mbay }
$$
a. mbù̀r lò-á
màjà
tā màjò
boule GEN-3SG.POSS be.good(CH) PRTCL INF.be.good(CD)
'Her 'boule' is very good.'
b. ji-í ì bòr tā bòr
hand-2SG.POss be $\operatorname{mud}(\mathrm{CH})$ PRTCL $\operatorname{mud}(\mathrm{CD})$
'Your hand is very muddy.' (Keegan 1997: 147) 
Equative predicates may also induce an apparently ranked reading, as indicated by the exclusive particle 'only' in the translation (whereby in this context, the relationship of 'father/paternal uncle' seems to be ranked higher than 'maternal uncle').

$$
\text { Mbay }
$$

\begin{tabular}{|c|c|c|c|c|}
\hline a. Súu & $n \bar{a} n-\dot{m}$ & $t \bar{a}$ & $n \bar{a} n-\dot{m}$ & nà \\
\hline Sur & be mat.uncle-1SG.POSS $(\mathrm{CH})$ & PRTCL & mat.uncle-1sG.POSs(CD) & $\mathrm{CNJ}$ \\
\hline$\grave{\imath}$ & bう̀̄̄-ḿ & & & \\
\hline be & father/pat.uncle-1sG.POSS NI & & & \\
\hline
\end{tabular}

Data of this kind suggests that it is the lexical content of the $\mathrm{CH}$ that is relevant to the scalar interpretation, rather than the relation encoded by the functional head $i$.

\subsubsection{Exclusive affectee focus}

The final type of exclusive focus to be discussed here is EXCLUSIVE AFFECTEE FOCUS. In Hausa (West Chadic; Nigeria, Niger), a CHDC can be used to delineate a particular subset of actants/referents affected by the action of the verb: 'the things or people in question constitute the exclusive set affected by the verb as opposed to those that are not' (Newman 2000: 92). This is exemplified in (37), where the $\mathrm{CH}$ is followed by the linker $n a$ and a CD.

\section{Hausa}

$\begin{array}{llll}\text { a. } & \text { sun hárbi } & \text { na } & \text { har̃bì } \\ \text { 3PL } & \operatorname{shoot}(\mathrm{CH}) & \text { LINK } & \operatorname{shoot}(\mathrm{CD})\end{array}$

'They shot the ones that were supposed to be shot.'

b. sunā sūkàn na sūkā

3PL.IPFV criticise(CH) LINK criticise(CD)

'They are criticising those who deserve to be criticised.' (Newman 2000: 92)

Again, examples of this kind have scalar semantics based around the exclusion of all participant groups other that those intended to be affected. The use of CHDCs to mark exclusive affectee focus appears to be substantially less common than exclusive purpose focus and exclusive situation focus.

\subsection{Summary}

The data presented here clearly demonstrate that CDs are employed in a variety of focus strategies in the languages of Africa. While the use of the same formal strategy to indicate verb/predicate focus and polarity focus is well attested cross-linguistically, the link between exclusive focus interpretations of CHDCs and verb/predicate focus is evident in languages that simultaneously make use of exclusive focus and verb focus constructions containing CDs. One such variety is the Kewe dialect of Kabiye (Gur; 
Togo) where CHDCs are used for exclusive purpose focus, as in (38), and exclusive situation focus and verb focus, as in (39). In each of these examples a focus particle $k i ́ / k u ́$ precedes the cognate infinitive. In (38) lack of ulterior purpose is expressed using a CHDC; the conventionalised interpretation of a CHDC involving the verb kom 'arrive' has a specific exclusive purpose focus reading.

Kabiye

$m i \eta-k \supset m-a ́$

kú $\quad k o m$

1SG-arrive-PFV(CH) FOC arrive.INF(CD)

'I have just come to say hello.' (there is no other reason for my visit)

(Collins \& Essizewa 2007: 191)

The same construction is reported to be widely used in natural speech to indicate exclusive situation focus and verb focus. For instance in (39a), the CD is used where the situation expressed by the $\mathrm{CH}$ is juxtaposed with a higher-ranked alternative (i.e. speaking is ranked higher on an ordered scale than understanding because the ability to speak a language also implies the ability to understand it). In (39b), the verb focussed in the negative clause is explicitly contrasted with the verb in the affirmative clause indicating exclusive situation focus.

$$
\text { Kabiye }
$$
a. ma-ní-U
ahuná kí ní-U
$m a-a$
1SG-understand-IPFV $(\mathrm{CH})$
Ewe FOC understand-INF(CD) 1SG-NEG
yood-U
kú siī
speak-IPFV it well
'I only understand Ewe, I do not speak it well...'

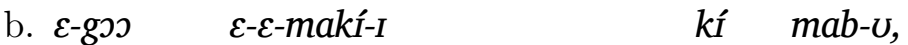
his-sister 3SG-NEG-beating-him(CH) FOC beat-INF(CD)
ع-lééy-ú $\quad n \varepsilon-I \quad k i ́$ lééy-ú
she-play-IPFV $(\mathrm{CH})$ with-him FOC play-INF(CD)
'His sister is not beating him, she's just playing with him.' (Collins \&
Essizewa 2007: 191)

Further evidence for the link between exclusive focus and verb focus can be seen in Ma'di. Here, the focus strategy used for indicating verb focus (discussed in §4.1) is also employed to indicate exclusive purpose focus, i.e. to indicate that 'an action has been performed for no particular reason' (Blackings \& Fabb 2003: 600). This is demonstrated by the alternative available translations of the example in (40). As with the examples in (15), the CD is marked for focus and occurs in a clause final position. 
$(40)$

$$
\begin{aligned}
& \text { Ma'di } \\
& \text { má fō fò } \\
& 1 \mathrm{SG} \quad \operatorname{say}(\mathrm{CH}) \text { say.FOC(CD) }
\end{aligned}
$$

(a) 'I said it.' (rather than communicating it in other ways)

(b) 'I just said it.' (for no apparent reason) (Blackings \& Fabb 2003: 600)

Examples of this kind suggest that exclusive purpose focus constructions may be a possible source for or development from the use of CDs in verb focus constructions. Together with the observation in the literature that verb focus and polarity focus are frequently indicated by the same structure with a single languages, the data presented in this section provides the foundation for a well motivated typology of the attested types of focus in CHDCs.

\section{Conclusions}

Cognate Head-Dependent Constructions (as defined in $\S 2$ ) are used for a range of interrelated grammatical functions, within a genetically diverse set of African languages. In this paper, we discussed two main types of CHDC evident in our sample. These can be broadly characterised as aspect-modifyng CHDCs and focus-modifying CHDCs.

First, we explored aspectual alternations marked by CHDCs (§3). We argued that the pluractional examples discussed coded the quantification of events and states, characterised in terms of iteration and frequency (e.g. Hausa, Kaamba, Mbay, Sheko), property proclivity (Mbay, Lango, Zuaran Berber), or scalar readings in which the presence of the CD relates to the successful achievement of an event goal (e.g. Classical Arabic, Kana, Izi) - in one case to its logical completion (Kanakuru). For the latter of these, the semantic interpretation was related to a high point on a scale relative to norm, indicating that semantic scales and individuation of events or event phases are crucial to the interpretation of the construction.

The second major use of CHDCs in African languages is to express various different types of focus $(\S 4)$. These were defined as verb/predicate focus, polarity focus and exclusive focus. We demonstrated that CHDCs are used widely to indicate verb/predicate focus (e.g. Akan, Ewe, Gidar, Gwari, Hdi, Lokạa Ma'di, Nupe, Suundi) and are found in an extensive range of languages in a syntactic position associated with focus. ${ }^{38}$ CHDCs are also used to indicate polarity focus where the truth value of a proposition is asserted, either in contrast to what has been asserted/presupposed or in agreement with it (e.g. Akye, Igbo, Lango, Mina). Furthermore, they are employed to indicate three different types of exclusive focus, whereby highly-ranked alternatives on an ordered scale are excluded. These were described as exclusive purpose focus (e.g. Acholi, Kabiye, Lango, Sheko), exclusive situation focus (e.g. Acholi, Mbay) and exclusive affectee focus (e.g. Hausa).

\footnotetext{
${ }^{38}$ While such structures are numerous in languages of West Africa, this may reflect a general tendency for the extension of existing cleft structures to CDs, rather than a development stemming from underlying in situ cognate objects (see for instance Hiraiwa 2005 and Kandybowicz 2008).
} 
The question remains open as to how these two functional macro-domains of CHDCs are connected logically or diachronically. As the aspectual and focus macro-types of CHDC functions may be marked by formally identical or related CHDCs, a diachronic connection indeed seems plausible if not likely. Scalar interpretations of events and their unfolding or attainment are relevant to all sub-types of "aspectual" uses of CHDCs as discussed in $\S 3$, in particular to high-ranked interpretations; they are also relevant to at least one type of focus encoding function of CHDCs discussed in $\S 4$, viz. exclusive purpose focus, where the orientation is rather to a low-ranked interpretation of possible interpretations on the scale. ${ }^{39}$ The scalar interpretation dimension that crucially refers to the lexical semantic content of the predicate links with the contextually or discourse-determined information structure interpretations, and thus the two macrotypes of functions of CHDCs can be plausibly linked. Evidence from the interpretation of a CHDC in specific individual languages, as in the Ewe example (19) discussed above, indicate that the interpretation of information focus or focal prominence for a clause may relate both to the lexical content of the verb in the predicate, as well as to iconically motivated focus on the scalar attainment of a goal. It is specifically with gradable property predicates where the link and overlap between scalar interpretation and exclusive situation focus is particularly salient, and may well be the point where the diachronic relation between the two functional subtypes is easiest to connect, as seen in the Mbay examples in (34) and (35). Defining and designing a specific plausible network model to capture these related tendencies and developments between the two macro-functional sub-types of CHDCs on a general level must remain the subject of another study, yet the present typology represents the first step to exploring this domain in a cross-linguistic perspective.

\section{Correspondence address}

Surrey Morphology Group, School of English and Languages, University of Surrey, Guildford, GU2 7XH, UK; e-mail: o.bond@surrey.ac.uk

\section{Acknowledgements}

We would like to thank participants at the following conferences and seminars for their

\footnotetext{
${ }^{39}$ Making reference to two seemingly opposite ends of a continuum or scale is not inherently a problem for connecting the two functional macro-types of CHDCs. Similar phenomena is encountered in another scalar phenomenon in language, viz. the grammaticalization paths associated with the development of specific auxiliaries in individual languages. Thus one finds such developments as a verb meaning 'go' becoming grammaticalised as a past and a future tense marker, or a verb meaning 'give' becoming grammaticalised in one and the same language to encode inceptive ('begin Verb-ing') and completive ('finish Verb-ing') semantics, as happened in the history of the Siberian Turkic language Xakas (Anderson 2004).
} 
helpful comments and suggestions on presentations contributing to this paper: 37th Annual Conference on African Linguistics in Eugene in April 2006; University of New Mexico Linguistics Departmental Seminar in Albuquerque in February 2009; World Congress of African Linguistics 6 in Cologne in August 2009; Linguistics Association of Great Britain Annual Meeting in Edinburgh in September 2009; Information Structure and Subordination: South America and Beyond in Nijmegen in April 2011; SOAS Linguistics Departmental Seminar in London in May 2011.

In particular we are grateful to Ines Fiedler, Jeff Good, Kristine Hildebrandt, Andrew Koontz-Garboden, Lutz Marten, Dejan Matić, Stuart McGill, Irina Nikolaeva, Sandy Ritchie, several anonymous LT reviewers and the LT editor, Frans Plank, for providing insightful discussion and feedback at various stages of this paper's development. All errors are, of course, our own.

\begin{abstract}
Abbreviations
$1=$ first-person, $2=$ second-person, $3=$ third-person, $\mathrm{ABS}=$ absolutive, $\mathrm{ACC}=$ accusative, $\mathrm{ADCL}=$ affirmative declarative, $\mathrm{AFOC}=$ argument focus, $\mathrm{CB}=$ clause boundary, $\mathrm{CD}=$ cognate dependent, $\mathrm{CH}=$ cognate head, $\mathrm{CHDC}=$ cognate head-dependent construction, CL1 $=$ class 1 agreement, $\mathrm{CNJ}=$ conjunction, $\mathrm{COMP}=$ complementizer, $\mathrm{DEF}=$ definite, $\mathrm{DEM}=$ demonstrative, $\mathrm{DEP}=$ dependent, $\mathrm{DS}=$ different subject, $\mathrm{FEM}=$ feminine, $\mathrm{FOC}=$ focus, $\mathrm{FUT}=$ future, GEN $=$ genitive, GER $=$ gerund, GO $=$ goal orientation, $\mathrm{HAB}=$ habitual, IMP $=$ imperative, $\mathrm{INDST}=$ indirect stance, $\mathrm{INF}$ $=$ infinitive, $\mathrm{IPFV}=$ imperfective, $\mathrm{LINK}=$ linker, $\mathrm{LOC}=$ locative case, MASC $=$ masculine, mat $=$ maternal, NEG $=$ negation, NMLZR $=$ nominalizer, $\mathrm{NOM}=$ nominative, $\mathrm{NPST}=$ non-past, $\mathrm{OBJ}=$ object, pat $=$ paternal, $\mathrm{PFV}=$ perfective, $\mathrm{PL}=$ plural, $\mathrm{POSB}$ $=$ possibility, $\mathrm{POSS}=$ possessive, $\mathrm{PRED}=$ predicator, $\mathrm{PREP}=$ preposition, $\mathrm{PROG}=$ progressive, $\mathrm{PRTCL}=$ particle, $\mathrm{PST}=$ past, $\mathrm{Q}=$ question, $\mathrm{REAL}=$ realis, $\mathrm{REL}=$ relativizer, $\mathrm{RED}=$ reduplication, $\mathrm{SBJ}=$ subject, $\mathrm{SBJV}=$ subjunctive, $\mathrm{SG}=$ singular, $\mathrm{SPF}=$ specific, $\mathrm{TOT}=$ totality, $\mathrm{UP}=$ upward movement, $\mathrm{VENT}=$ ventitive.
\end{abstract}




\section{References}

Aboh, Enoch Oladé, Katharina Hartmann \& Malte Zimmermann. 2007. Focus and grammar: the contribution of African languages. In Enoch Oladé Aboh, Katharina Hartmann \& Malte Zimmermann (eds.), Focus strategies in African languages: the interaction of focus and grammar in Niger-Congo and Afro-Asiatic, 1-14. Berlin: Walter de Gruyter.

Ameka, Felix. 2010. Information packaging in Kwa: micro-variation variation and typology. In Enoch O. Aboh \& James Essegbey (eds.), Topics in Kwa syntax, 141-176. Dordrecht: Springer.

Amha, Azeb. 2001. The Maale language. Leiden: CNWS Publications.

Anderson, Gregory D. S. 2004. Auxiliary Verb Constructions in Altai-Sayan Turkic. Wiesbaden: Harrassowitz Verlag.

Blackings, Mairi John \& Nigel Fabb. 2003. A grammar of Ma'di. Berlin: Walter de Gruyter.

Bogny, Yapo Joseph. 2005. Kwa disyllabic verbs: an approach through focus characteristics. In M. E. K. Dakabu \& E. K. Osam (eds.), Studies in the languages of the Volta Basin 3, 25-32. Legon: Department of Linguistics, University of Ghana.

Bolinger, Dwight. 1965. Forms of English. Cambridge, MA: Harvard University Press.

Bouka, Léonce-Yembi. 1989. Eléments de description de kaamba. parler bantou de la république populaire du congo (groupe koongo, h17b). Université Libre de Bruxelles.

Bybee, Joan, Revere Perkins \& William Pagliuca. 1994. The evolution of grammar: tense, aspect and modality in the languages of the world. Chicago: University of Chicago Press.

Collins, Chris \& Komlan E. Essizewa. 2007. The syntax of verb focus in Kabiye. In Doris L. Payne \& Jamie Peña (eds.), Selected Proceedings of the 37th Annual Conference on African Linguistics, 191-203. Somerville, MA: Cascadilla Proceedings Project.

Corbett, Greville G. 2000. Number. Cambridge: Cambridge University Press.

Cusic, David Dowell. 1981. Verbal plurality and aspect. Stanford, CA: Stanford University $\mathrm{PhD}$ dissertation.

Dalrymple, Mary \& Irina Nikolaeva. 2011. Objects and information structure: agreement, casemarking and grammatical function. Cambridge: Cambridge University Press.

Dressler, Wolfgang. 1968. Studien zur verbalen Pluralität: Iterativum, Distributivum, Durativum, Intensivum in der allgemeinen Grammaitik, im Lateinischen und Heithitischen (Österreichische Akademie der Wissenschaften: Philosophisch-historiche Klasse: Sitzungberichische, 259 Band, 1. Abhandlung). Vienna: Hermann Böhlaus Nachf. 
Ermisch, Sonja (ed.). 2009. Focus and topic in African languages (Franfurter Afrikanistishe Blätter 18). Cologne: Rüdiger Köppe.

Faraclas, Nicholas. 1984. A grammar of Obolo. Bloomington, IN: Indiana University Linguistics Club.

Faraclas, Nicholas. 1989. Cross River. In John Bendor-Samuel (ed.), The Niger-Congo languages, 377-399. Lanham, MD: University Press of America.

Faraclas, Nicholas \& Kay Williamson. 1984. Assimilation, dissimilation and fusion: vowel quality and verbal reduplication in Lower Cross. Journal of African Languages and Linguistics 6. 1-18.

Fiedler, Ines \& Anne Schwarz (eds.). 2006. Papers on information structure in African languages (ZAS Papers in Linguistics 46). Berlin: ZAS.

Fiedler, Ines \& Anne Schwarz (eds.). 2010. The expression of information structure. Amsterdam; Philadelphia: John Benjamins.

Frajzyngier, Zygmunt. 2008. A grammar of Gidar. Frankfurt: Peter Lang.

Frajzyngier, Zygmunt, Eric Johnston \& Adrian C. Edwards. 2005. A grammar of Mina. Berlin: Mouton de Gruyter.

Frajzyngier, Zygmunt \& Erin Shay. 2002. A grammar of Hdi. Berlin: Walter de Gruyter.

Fufa, Tolemariam. 2009. A typology of verbal derivation in Ethiopian Afro-Asiatic languages. Utrecht: LOT Publications.

Goldberg, Adele \& Farrell Ackerman. 2001. The pragmatics of obligatory adjuncts. Language 77(4). 798-814.

Hadermann, Pascale. 1996. Grammaticalisation de la structure infinitif + verbe conjugué dans quelques langues bantoues. Studies in African Linguistics 25(2). 155-169.

Hale, Ken, Ụzọdịnma Peter Ihiọnụ \& Victor Manfredi. 1995. İgbo bipostional verbs in a syntactic theory of argument structure. In Akinbiyi Akinlabi (ed.), Theoretical approaches to African linguistics, 83-108. Trenton, NJ: Africa World Press.

Hale, Ken \& Samuel Jay Keyser. 2002. Prolegomenon to a theory of argument structure. Cambridge, MA: MIT Press.

Halliday, M. A. K. 1967. Notes on transitivty and theme, part 2. Journal of Linguistics 3(2). 199-244.

Heath, Jeffrey. 2008. A grammar of Jamsay. Berlin; New York: Mouton de Gruyter.

Hellenthal, Anne-Christie. 2010. A grammar of Sheko. Utrecht: LOT Publications. 
Hiraiwa, Ken. 2005. Predicate clefts in Buli: categories and phases. Linguistic Analysis. A special volume: African Linguistics in the New Millennium 32(3). 544-583.

Hutchinson, John P. 2000. Predicate focusing constructions in African and diaspora languages. In H. Ekkehard Wolff \& Orin D. Gensler (eds.), Proceedings of the 2nd World Congress of African Linguistics, Leipzig 1997, 577-591. Cologne: Rüdiger Köppe.

Hyman, Larry M. \& Daniel J. Magaji. 1970. Essentials of Gwari grammar. Ibadan: University of Ibadan Institute of African Studies.

Hyman, Larry M. \& John R. Watters. 1984. Auxiliary focus. Studies in African Linguistics 15(3). 233-273.

Ikoro, Suanu. 1996. The Kana language. Leiden: CNWS Publications.

Jaggar, Philip J. 2001. Hausa. Amsterdam; Philadelphia: John Benjamins.

Jespersen, Otto. 1924. The philosophy of grammar. London: George Allen and Unwin Ltd.

Kandybowicz, Jason. 2008. The grammar of repetition: Nupe grammar at the syntaxphonology interface. Amsterdam; Philadelphia: John Benjamins.

Keegan, John M. 1997. A reference grammar of Mbay. Munich: Lincom Europa.

Kennedy, Christopher \& Louise McNally. 2005. Scale structure and the semantic typology of gradable predicates. Language 81(2). 345-381.

Kiss, Katalin É. 1998. Identificational focus versus information focus. Language 74(2). $245-273$.

Kitching, A. L. 1932. An outline grammar of the Acholi language. London: Sheldon Press.

Kuno, Susumu \& Ken'ichi Takami. 2004. Functional constraints in grammar: on the unergative-unaccusative distinction. Amsterdam; Philadelphia: John Benjamins.

König, Ekkehard. 1991. The meaning of focus particles. London: Routledge.

Lambrecht, K. 1994. Information structure of sentence form: a theory of topic, focus and the mental representations of discourse referents. Cambridge: Cambridge University Press.

Lefebvre, Claire \& Anne-Marie Brousseau. 2002. A grammar of Fongbe. Berlin; New York: Mouton de Gruyter.

Levin, Beth \& Malka Rappaport Hovav. 1994. Unaccusativity: at the syntax-lexical semantics interface. Cambridge, MA: MIT Press.

Malandra, Alfred. 1952. A new Acholi grammar. Nairobi: Eagle Press. 
Manfredi, Victor. 1991. Ágbọ and Éhugbò - İgbo linguistic consciousness, its origins and limits. Cambridge, MA: Harvard University $\mathrm{PhD}$ dissertation.

Matić, Dejan \& Irina Nikolaeva. 2009. Focusing beyond the word: Polarity Focus from a typological perspectives. Association for Linguistic Typology 8th Biennial Meeting, University of California, Berkeley, July 2009.

Meier, John, Inge Meier \& J. Bendor-Samuel. 1975. A grammar of Izi: an Igbo language. Norman, OK: Summer Institute of Linguistics.

Mitchell, Terence Frederick. 2009. Zuaran Berber (Libya): grammar and texts (Berber Studies 26). Cologne: Rüdiger Köppe.

Mycock, L. 2007. Constituent question formation and focus: a new typological perspectives. Transactions of the Philological Society 105(2). 193-251.

Newman, Paul. 1974. The Kanakuru language. Leeds: The Institute of Modern English Language Studies in association with the West African Linguistics Society.

Newman, Paul. 2000. The Hausa language: an encyclopedic reference grammar. New Haven, CT: Yale University Press.

Nikolaeva, Irina. 2013. Unpacking finiteness. In Dunstan Brown, Marina Chumakina \& Greville G. Corbett (eds.), Canonical morphology and syntax, 99-123. Oxford: Oxford University Press.

Noonan, Michael. 1992. A grammar of Lango. Berlin: Mouton de Gruyter.

Polinsky, Maria. 1999. Review of information structure and sentence form: topic, focus, and the mental representations of discourse referents by Knud Lambrecht. Cambridge: Cambridge University Press, 1994. Language 75(3). 567-582.

Romero, Maribel \& Chung-hye Han. 2004. On negative yes/no questions. Linguistics and Philosophy 27(5). 609-658.

Rooth, Mats. 1992. A theory of focus interpretation. Natural Language Semantics 1(1). $75-116$.

Savage, G. A. R. 1956. The essentials of Lwo (Acoli). Nairobi: East African Literature Bureau.

Schuh, Russell G. 1998. A grammar of Miya. Berkeley; Los Angeles: University of California Press.

Selkirk, Elizabeth. 1984. Phonology and syntax: the relation between sound and structure. Cambridge, MA: MIT Press.

Storch, Anne. 2009. Hone. In Gerrit J. Dimmendaal (ed.), Coding participant marking: construction types in twelve African languages, 213-240. Amsterdam; Philadelphia: John Benjamins. 
Urua, Eno E. 1997. Object movement in eastern Lower-Cross. In Rosemarie Déchaine \& Victor Manfredi (eds.), Object position in Benue-Kwa, 189-206. The Hague: Holland Academic Graphics.

Versteegh, Kees. 2001. The Arabic language. Edinburgh: Edinburgh University Press.

Williamson, Kay. 1986. Niger-Congo: SVO or SOV. Journal of West African Languages 16(1). $5-14$.

Wolff, H. Ekkehard. 2003. Predication focus in Chadic languages. In Dymitr Ibriszimow, Henry Tourneux \& H. Ekkehard Wolff (eds.), Topics in Chadic Linguistics. Papers from the 1st Biennial International Colloquium on the Chadic Language Family, Leipzig 2001 (Chadic Linguistics/Linguistique Tchadique/Tschadistik 1), 137-159. Cologne: Rüdiger Köppe.

Xrakovskij, Viktor S. 1997. Typology of iterative constructions. Munich: Lincom Europa.

Zimmermann, Malte \& Daniel Hole. 2008. Predicate focus, verum focus, verb focus: similarities and differences. Predicate Focus Workshop, University of Potsdam, November 2008. 